\title{
If happiness is relative, against whom do we compare ourselves? Implications for labour supply
}

\author{
Eduardo Pérez-Asenjo
}

\begin{abstract}
This paper addresses two important issues: the nature of the reference group to which individuals compare themselves, and the implications of social comparisons for labour supply. It identifies age as the main characteristic defining the reference group. Race, sex and religion are other relevant features in its determination. It provides micro-level evidence that social comparisons influence the hours an individual works. Specifically, if her income is lower than her reference group income, she will work more. It also shows that for males, white people and people living in rural areas the effect of relative income on both happiness and labour supply is greater.
\end{abstract}

Keywords Happiness $\cdot$ Labour supply $\cdot$ Relative income

JEL Classification D01 $\cdot \mathrm{D} 19 \cdot \mathrm{J} 22$

E. Pérez-Asenjo ( $\square)$

Chief Economist Team, Spanish Competition Authority, Barquillo 5, 28004, Madrid, Spain

e-mail: eperez@cncompetencia.es

E. Pérez-Asenjo

Economics Department, University Carlos III, Getafe, Madrid, Spain 


\section{Introduction}

Everybody wants to be happy. We want money (or anything else) only as a means to increase our happiness. If having more money does not substantially increase our happiness, then money is not very important, but happiness is. It could be argued that while happiness is important per se, economic things only count as long as they make people happier.

The behaviourist revolution in psychology and the ordinalism revolution in economics in the 1930s pushed the study of happiness further and further out of sight. While psychologists have returned with strength to the study of feelings (explaining, measuring and comparing them across people), economics now starts to look to the issue of happiness. Richard Easterlin $(1973,1974)$ was the first to call economists attention to survey data that illuminate the relationship between material living standards and subjective well-being. He noted that despite huge growth in real per capita income in several countries after World War II, individual happiness measured in different surveys had not increased. However, he also found evidence that at a given point in time, and within a particular country, persons with higher income were happier. His pathbreaking contribution was not followed then, but in recent years, some economists are trying to solve what has been called the Easterlin paradox. This is opening the way to an extremely attractive new field of research.

In traditional economic models, higher income expands individuals' opportunity set and as more goods and services can be consumed, it leads inevitably to higher levels of utility. Thus, we need an expanded model if we are to explain what is happening. We need to incorporate the standard findings of modern psychology. The most obvious of these is the fact that we compare our incomes with those of others. Then, the answer could be that riches do bring happiness, provided that you are richer than other people. It is not the absolute level of income that matters most but rather one's position relative to other individuals. The question of getting ahead in the income hierarchy depends in part on how many hours the individual supplies in the labour market. Working more hours at the expense of leisure time may well decrease happiness. Therefore, if the quest for relative standing make people work more hours (which increases income but decreases happiness), it can explain the Easterlin paradox. Thus, a sensible hypothesis is to test if relative income or position can affect both happiness and labour supply.

Furthermore, there is another reason to study the effect of relative income on happiness and labour supply together in the same paper. The effect of relative income on labour supply may be due to network or informational concerns. Job information transmission within a social network can make an individual's reference group income informative about her own future income prospects. According to this alternative view, if the individual's reference group income increases, the individual will react to this opportunity signal redoubling her efforts to attain a higher income. Thus, we can observe the same positive relation between other's income and own hours of work corresponding to two alternative interpretations, relative deprivation or signal effects. 
Self-reported well-being data may allow for discrimination between these competing explanations. If the income of the reference group is negatively related to individual happiness, it suggests the social comparisons explanation, while if the relation is positive, it would point to the signal effect. In this latter case, it also would demonstrate the so-called Hirschamn's 'tunnel-effect' (Hirschman and Rothschild 1973): people can derive utility from other's higher income if they consider it to be informative about their own future income.

As we will see in the next section, the majority of the growing literature which reviews the relationship between income and happiness finds a negative relation between other's income and own happiness (see, for example, Ferreri-Carbonell 2005). However, in some papers (see, for example, Senik 2004) it is found a positive relation, which the authors attribute to the Hirschamn's 'tunnel-effect'. In this paper I find a significant negative relation between the income of the reference groups and individual happiness. Hence the effect on labour supply, if any, would arise as a consequence of social comparisons. In the second part of the paper, I find that, indeed, relative income has a significant effect on the amount of labour an individual is willing to supply. As expected, if the income of an individual is below the income of her reference group, she will work more hours to surpass, catch or keep up with them.

A crucial question in all this analysis is to identify the nature of the reference groups. The reference group is defined as the group of people an individual looks onto when making social comparisons. In the first part of the paper, making use of the valuable information contained in the self-reported wellbeing data, I identify the characteristics that define the reference group. The reference groups defined by these characteristics are then used in the second part of the paper in the estimation of the relative income effect on labour supply. This second part is relevant not only for the implications for labour supply but also as a validity test for the conclusions of the first part and the reliability of self-reported happiness data.

\section{The long history of social comparisons}

There is a large literature in sociology and psychology that acknowledges the fact that social comparisons affect individual happiness. In sociology, we can find the concepts of relative deprivation, relative status and social frame of reference. What these concepts share is the notion that individuals operate within reference groups. Even within the field of economics, these factors have been taken into account. Nobel prize winner Gary Becker's (1974) famous article $A$ Theory of Social Interactions finished contrasting Thorstein Veblen and Adam Smith's views of the world. If there were a rise in all incomes in a community by the same percentage, would it improve a typical person's welfare? In Smith's world the answer would be yes, while in Veblen's world the answer would be no. The negative comes from Veblen's belief that the welfare of a typical person primarily depends on her relative income position, and a rise in the environment and own income by the same percentage wouldn't 
have changed this relative position. ${ }^{1}$ Following his argument in the same book Veblen fashioned the notion of conspicuous consumption, serving to impress other persons. In fact, Smith himself believed that the primary purpose of wealth-accumulation beyond a minimal level was not for consumption, but for the social attention. ${ }^{2}$ In 1949 Duesenberry formulated the relative income hypothesis which asserts that individual utility depends both on absolute and relative income. Following this line of thought, the models of interdependent preferences (see, for example, Pollak 1976) assume that agents derive utility from what one achieves in comparison with others. Thus, individual happiness and satisfaction depend not only on the material achievements and income in absolute terms but also on one's relative position.

The recent growth of the empirical literature on happiness and income supply much information in this respect. The majority of these articles coincide in signaling a negative and significant relationship between own happiness and other's income. Nonetheless, there are three papers which find a positive happiness effect from other's income. Senik (2004), using the Russian Longitudinal Monitoring Survey (RLMS), explains this positive relation as an information or tunnel effect. She argues that other's higher incomes may be considered informative about own future income, thus increasing current happiness. In Senik (2008) she finds a positive effect in new eastern European post-transition countries and in the United States, while the effect is negative in old western European countries. She argues that the information effect is higher in high uncertainty countries (new Europe) and in high mobility countries (US). Finally, Kingdon and Knight (2007) find a positive relation between happiness and income of others in the local residential area, while the effect is negative when the reference group is widened to include the whole district. They explain it in terms of altruism or fellow-feeling in a close community.

By contrast, the rest of this burgeoning literature points directly to the negative influence of other's income on happiness and attributes it to social comparison considerations. The evidence is consistent along various countries and robust to different definitions of the reference groups. ${ }^{3}$ In American data, Luttmer (2005) using the National Survey of Families and Households and

\footnotetext{
${ }^{1}$ 'The desire for wealth can scarcely be satiated in any individual instance, and evidently a satiation of the average or general desire for wealth is out of the question. However widely, or equally, or foully, it may be distributed, no general increase of the community's wealth can make any approach to satiating this need, the ground of which is the desire of everyone to excel everyone else in the accumulation of goods' (Veblen 1899, my italics).

2'What are the advantages which we propose by that great purpose of human life which we call bettering our condition?' Smith asked. "To be observed, to be attended to, to be taken notice of with sympathy, complacency, and approbation, are all the advantages which we can propose to derive from it. It is the vanity, not the ease, or the pleasure, which interests us."(Smith 1759, my italics).

${ }^{3}$ For a detailed summary see the literature surveys in Frey and Stutzer (2002), Layard (2005a) and Clark et al. (2008). In the sphere of job satisfaction, instead of happiness, the evidence also points to a negative effect of other's income. See Clark and Oswald (1996), and Sloane and Williams (2000), using British data, or Lévy-Garboua and Montmarquette (2004) using Canadian data.
} 
the Census, finds a negative relation using the neighbours as the reference group. McBride (2001) and Blanchflower and Oswald (2004) use the same data used in this paper, the US General Social Survey (GSS). McBride presents an empirical analysis to test for the effect of own income, past financial situation and comparison income on self-reported happiness. He defines comparison income as average earnings of the individual's cohort. He finds a negative correlation between happiness and both comparison income and the financial situation of the parents. Blanchflower and Oswald study the effect on subjective well-being of different variables such as age, race or sex. They also report a negative correlation between subjective well-being and comparison income. Their comparison income is defined as the average income in the state where the individual lives. My findings are in line with the results of these two articles and hence contrary to Senik (2008). ${ }^{4}$ I provide evidence that there is a strong negative and statistically significant link between happiness and reference group income for all the reference groups considered. Therefore, I do not find evidence of information or tunnel effects, and I provide support for the existence and relevance of social comparisons.

All these studies treat people's reference groups as given. They impose a particular reference group, and then prove that the income of this group is negatively and significantly correlated with the happiness of the individual. Two exceptions that employs respondent-defined rather than researcher-defined reference groups are Melenberg (1992) and Knight et al. (2006). Melenberg uses 1985 and 1986 Dutch Socio-Economic Panel data in which individuals were asked about the 'people whom they meet frequently'. He shows that the average income of this people had a positive effect on income aspirations (proxied by the amount of income considered good or adequate). Knight et al. directly asks 9,200 Chinese rural households against whom they compare themselves. Respondents were given eight possibilities geographically enlarging, from neighbours to people in China as a whole. ${ }^{5}$ Almost $30 \%$ chose their neighbours, while almost $40 \%$ selected fellows in their own village to be their reference group.

Thus, despite the overwhelming evidence of the influence of comparison income on happiness, little is known about the characteristics and the definition of the group to which individuals compare themselves. In this paper, once I check that relative income matters for happiness, I try to identify the characteristics which define the reference group. In a similar fashion, Senik (2009) evaluates the relative importance of different types of benchmark using the Life in Transition Survey (a cross-section survey of all countries of the former socialist bloc). She finds that internal comparisons to one's own past living standard outweigh any other comparison benchmark. Nonetheless,

\footnotetext{
${ }^{4} \mathrm{~A}$ possible explanation for the opposing results among the papers may lie in the composition of the reference groups, which in Senik (2008) are specially constructed to contain information effects.

${ }^{5}$ Specifically, the eight possibilities are neighbours, relations, fellow-villagers, people in township, people in county capital, people in cities, people in China as a whole, and difficult to say.
} 
external comparisons are also relevant, and she shows that local comparisons (to one's parents, former colleagues or high school mates) are more powerful than self-ranking in the social ladder. In this paper, I only deal with external references and comparing their relative importance I conclude that age, race, sex and religion are the most relevant characteristics defining the reference groups.

In a related line of research, there is a growing recognition in some recent macroeconomic literature of the role of positional concerns in consumption. A widely used model giving emphasis to positional concerns is the keeping up with the Joneses model (see, for example, Gali 1994). This model assumes that agents derive utility from their own consumption as well as from the difference or comparison between their own and aggregate per capita consumption. We rely on this general framework to study the implications of social comparisons for hours worked. In particular, I am more precise since I make use of the Joneses found in the first part to test their importance on labour supply.

There are a few previous papers that have examined the role of relative income in labour supply. Both Neumark and Postlewaite (1998) and Park (2005) study if the women's decisions to seek paid employment depend on the employment decisions of other people with whom relative income comparisons might be important. Neumark and Postlewaite report that women's employment decisions are positively related to their sisters' employment decisions. Park finds evidence that married women are more likely to be in labour force when their husbands' relative income is low. In a related work, Bowles and Park (2005) show that greater inequality predicts longer average work hours, using country-level macro data on work hours in OECD countries, which they attribute to comparison or Veblen effects. Stark and Taylor $(1989,1991)$ find that relative income plays a significant role in international migration from Mexico to United States. Individuals who can keep other people in their poorer country of origin as their reference group are more likely to migrate than those who will compare with their richer new neighbours.

In this paper I follow both lines of research, and I provide evidence that relative income is a significant variable to explain both happiness and labour supply. The negative effect of the reference group income on happiness and the positive effect on labour supply indicate that social comparisons are the cause of both effects. If social comparisons exist and affect human feelings and behaviour, the next natural question to be asked is, against whom do we compare ourselves? In this article I identify the main characteristics defining the Joneses. The paper shows that the reference group against which the individual can evaluate himself is primarily defined by age, while other relevant features are race, sex and religion. Besides, it identifies the groups who care more about social comparisons. The effect of relative income on both happiness and labour supply is greater for males, white people and people living in the country. Finally, the paper includes three different measures of relative income to test the hypothesis of social comparison effects. One of them is referred to income rank, which is not usually tested in this literature, and I provide empirical evidence for its importance on individual happiness. 


\section{Data}

Despite the increasing number of studies revised in the previous section which use subjective survey data, there are still justifiable concerns among economists about the use of self-reported measures of well-being. Reported subjective well-being may depend on the order of questions, the phrasing of questions, the scales applied, the respondent's mood at the time of the survey, the selection of information processed or the context in which the survey is conducted (see Bertrand and Mullainathan 2001; Ravallion and Lokshin 2001). However, a growing evidence from both economists and psychologists shows that these measures of individual well-being contain 'substantial amounts of valid variance', ${ }^{6}$ and are predictive of observable behaviour.

Well-being data pass what psychologists often call validation exercises since they are correlated with observable phenomena. For example, people who report higher happiness scores tend to laugh and smile more, are more likely to be rated as happy by friends, have relatively greater electrical activity in the left prefrontral region of the brain ${ }^{7}$ and correlate negatively with heart rate and blood pressure measures of responses to stress. ${ }^{8}$ Besides, different measures of well-being correlate well with one another. Therefore, the existing research suggests that what the psychologists call subjective well-being is a real phenomenon and the data which asks about it are reliable enough for the econometrical work. Moreover, as already noted, two of the papers commented in the previous section (McBride 2001; Blanchflower and Oswald 2004) use the same survey used in this paper, the US General Social Survey (GSS).

The GSS is a survey of US households conducted by the National Opinion Research Center in almost every year between 1972 and 1993, ${ }^{9}$ and every other year since 1994. Each survey is an independently drawn sample of persons aged 18 or over living in the US, who are personally interviewed. I use the cumulative data file, prepared by the Roper Center for Public Opinion Research, which merges all the years of the GSS into a single file.

The individuals sampled are different each year, so the cumulative data file is not a panel but 25 different cross sections corresponding to the 25 years. For the first years of the survey there are around 1,500 observations per year, while there are roughly 3,000 observations for the latest years beginning in 1994, when the survey became biannual. We have data for 46,510 individuals about a very wide range of variables, including happiness, individual and family income, hours worked, sociodemographic characteristics, union membership

\footnotetext{
${ }^{6}$ In the words of the most cited psychologist in this field, Ed Diener (1984, p. 551).

${ }^{7}$ The left prefrontal region of the brain is rich in receptors for the neurotransmitter dopamine, higher concentrations of which have been shown to be correlated with positive affect.

${ }^{8}$ For surveys of this evidence see Frank (1985b, Chapter 2) and Clark and Oswald (1996). A more thorough discussion of the realibility of self-reported happiness data is included in Frey and Stutzer (2002) and Clark et al. (2008).

${ }^{9}$ The survey was not conducted in the years 1979, 1981 and 1992.
} 
and health condition. Thus, these data allow to further include a large set of control variables related to individual sociodemographic and socioeconomic characteristics, which may significantly explain some of individual's general satisfaction. The GSS, except for the US Census, is the most frequently analysed source of information in the social sciences, so it needs no further explanation.

The summary statistics of the most relevant variables of our sample are presented in Table A1 in the Appendix 2 (see Supplementary material). For the variables I have chosen that could define the reference groups, I present the number of observations of each category for the two main estimations in this paper, the one for happiness and the one for hours worked. These variables are race, sex, place of living, marital status, work status, religion, political views, occupation, education, prestige, age and region. In this table we can see the heterogeneity of the respondents which shows that the GSS is a representative sample survey of the adult American population.

The dependent variable in the first part of the analysis, happiness, is extracted from the following question, 'Taken all together, how would you say things are these days: would you say that you are very happy, pretty happy, or not too happy?'. In the paper, the responses are coded as (3) Very Happy, (2) Pretty Happy, and (1) Not too Happy. ${ }^{10}$ Thus, we observe three discrete response outcomes coming from the question, which make it suitable to use the methodology explained in the next section. In general, we can see that American people have considered themselves pretty happy along these previous years: $32 \%$ of the respondents answer that they are very happy, more that $55 \%$ answer that they are pretty happy, while $12 \%$ of those interviewed in the GSS describe themselves as not too happy. For both individual and family income respondents did not record exact income figure, but were asked to identify the income range they fell into. These quantities are in constant dollars with base in 1986. In the question about health, respondents are asked to answer if they consider their condition of health to be excellent, good, fair or poor. The average is very close to the answer good.

\section{Model for happiness}

Most basic models used in the micro theory of consumption and production assume that individual utility functions are not influenced by the behaviour of others. In contrast, major parts of psychology and sociology assume that preferences of economic agents, and then happiness, are partly determined by comparison with relevant others. We assume the relative income hypothesis, a preference hypothesis that states that individuals care about relative income as well as about the income level itself.

\footnotetext{
${ }^{10}$ For ease of interpretation, I have reversed the scaling contained in the GSS, and within the paper the number 3 represents the highest level of happiness.
} 
In the light of this hypothesis I write a simple model in which the utility of the individual depends not only on her own income but also on the income of her reference group.

$$
u\left(y_{i}, \bar{y}_{i}, x_{i}\right)
$$

where $u$ is utility of an individual, $y_{i}$ is her income, $\bar{y}_{i}$ is the income of her reference group and $x_{i}$ is a vector of other variables which affect her utility. The decision of which variables $x_{i}$ have to be included is based on both the economic and the psychological literature and on data availability.

It is assumed, as seems plausible, that $u_{i}$ is a function that is observable only to the individual. Its structure cannot be conveyed unambiguously to the interviewer or any other individual. The idea used in this paper is that there is a relation between actual utility $\left(u_{i}\right)$ and the happiness expressed in a survey $\left(H_{i}\right)$, defined by the equation:

$$
H_{i}=u\left(y_{i}, \bar{y}_{i}, x_{i}\right)+\varepsilon_{i}
$$

where the error term captures the unobservable heterogeneity across individuals. It includes among other things, the genetic or social factor which make human beings experience different levels of happiness even facing the same circumstances, and the inability of individuals to communicate accurately their happiness level. This approach recognises the economist's instinctive distrust of a single person's subjective happiness.

We observe, as already noted, three discrete response outcomes. The latent continuous variable is happiness $\left(H_{i}\right)$ and the correspondence with the three discrete responses in the survey $\left(H_{i}^{*}\right)$ will be given by:

$$
H_{i}^{*}=\left\{\begin{array}{l}
1 \text { if } H_{i}<c_{1} \\
2 \text { if } c_{1} \leqslant H_{i} \leqslant c_{2} \\
3 \text { if } H_{i}>c_{2}
\end{array}\right.
$$

This structure makes it suitable for estimation by maximum likelihood using the ordered logit procedure. Through this method the data are treated ordinally so that higher reported happiness reflects higher happiness of an individual. Hence I do not assume, as most of the psychological literature does (which assigns numbers to happiness levels and then uses OLS regression methods), that the answers to happiness surveys are cardinal and interpersonally comparable. Ordinal comparability implies that individuals share a common opinion of what happiness is. Most of the papers cited in the literature use ordered latent response models ${ }^{11}$ rather than OLS. However, Ferrer-iCarbonell and Frijters (2004) argue that the use of ordered discrete dependent variable methods or OLS makes little different to the results.

\footnotetext{
${ }^{11}$ Some of them use ordered logits while others estimate ordered probits, which is a trivial modification of the formulation and makes virtually no difference in practice.
} 


\subsection{Identification of social comparison effects}

Studies of social comparison processes (Festinger 1954) suggest that individuals compare themselves primarily to others who are similar or whom they come into close daily contact. Besides, I consider characteristics related to social achievement and status, and also characteristics that are relevant to an individual self-conception as candidates to define the reference groups. Thus I have chosen twelve different characteristics that divide the human population in different groups with common features, which make every group identifiable and distinguishable from the other groups created by the same characteristic. Hence, they are suitable of becoming a comparison point against which the individual can evaluate himself. They are: age (people in intervals of ten years), sex, race (just blacks and whites), educational degree (with five different categories), region (with nine different regions in USA), work status (with four different categories), marital status (with four different categories), occupation (with five different categories), prestige (with five different categories), religion (with four different categories), political views (with three different categories), and place of living (people living in the city versus people living in the country). The definition of the reference groups is exhaustively revised in Appendix 1 (see Supplementary material). ${ }^{12}$

The majority of these characteristics also affect individual's happiness and thus are included as controls in the equations of the happiness literature. ${ }^{13}$ Hence, the characteristics that define the reference group have a double effect, direct and indirect, on individual's happiness. This generates a problem of identification as Manski (1993) illustrates. To show the problem I present the equation to identify the social comparison effects:

$$
H_{i}=\theta y_{i}+\beta g\left(y_{i}, Z_{i}\right)+\gamma^{\prime} Z_{i}+\eta^{\prime} x_{i}+\varepsilon_{i}
$$

where $H_{i}$ is happiness of an individual, $y_{i}$ is her income, $Z_{i}$ are characteristics that define her reference group, $g\left(y_{i}, Z_{i}\right)$ is a 'status function' which aims to capture the effect of relative income, and $x_{i}$ are other individual characteristics which control for other determinants of happiness.

The problem is to delimit the contextual effects (the propensity of an individual to be more or less happy varies with exogenous characteristics of her reference group $g\left(y_{i}, Z_{i}\right)$, captured by $\beta$ ) and the correlated effects (the propensity of an individual to be more or less happy varies with the characteristics which define her reference group $\left(Z_{i}\right)$, captured by $\left.\gamma\right)$. I want to

\footnotetext{
${ }^{12}$ In some cases, as will be explained below, the limited number of observations determines the categories into which every characteristic is divided.

${ }^{13}$ For example, age, sex, race, work characteristics, years of education and marital status are included as controls in Blanchflower and Oswald (2004), in what they believe to be one of the first microeconometric happiness equations. Luttmer (2005) also includes religion, and other studies such as Ferrer-i-Carbonell (2005), McBride (2001) or Helliwell (2002) include a similar set of controls.
} 
separate the component of $Z_{i}$ which affects happiness due to social comparison considerations, so the coefficient of interest will be $\beta$.

To make this descomposition possible, i.e., for $\beta$ and $\gamma$ to be identified, we require two conditions:

(1) The only way $y_{i}$ and $Z_{i}$ can jointly affect $H_{i}$ is directly (captured by $\theta$ and $\gamma$, respectively) and through the term of contextual effects (captured by $\beta$ ). In other words, there is no other term containing $y_{i}$ and $Z_{i}$ which affects $H_{i}$.

(2) The function which captures the contextual effects, $g\left(y_{i}, Z_{i}\right)$, must be nonlinear in $Z_{i}$ because if it were linear there would be a problem of perfect multicollinearity which would make it impossible to identify $\beta$ and $\gamma$.

Thus, I have constructed two variables of relative income which have individual variability and satisfy these conditions. The first variable is the income of the individual divided by the income of her reference group (Eq. 4).

$$
H_{i}=\theta y_{i}+\beta \frac{y_{i}}{E\left(y_{i} / Z_{i}\right)}+\gamma^{\prime} Z_{i}+\eta^{\prime} x_{i}+\varepsilon_{i}
$$

In the literature it is usual just to use the reference group income as the variable capturing the social comparison effects. However I use the income of the individual divided by the income of her reference group because it appears as an argument in the optimal labour supply decision in my model of the second part. Thus, I test the effects of the same variable on both happiness and labour supply.

The second variable is the percentile where an individual stays in the income distribution of her reference group (Eq. 5).

$$
H_{i}=\theta y_{i}+\beta F\left(y_{i} / Z_{i}\right)+\gamma^{\prime} Z_{i}+\eta^{\prime} x_{i}+\varepsilon_{i}
$$

The issue of income rank has received little direct attention in this context. However, it seems sensible to think that an individual may be influenced not just by relative income but by the rank-ordered position (measured by the percentile) of her income within her reference group. In a recent study, Brown et al. (2008), using data from the British Workplace Employee Relations Survey (WERS) show that satisfaction depends upon the ordinal rank of an individual's wage within a comparison group. In a more general way, Parducci (1995) presents the contextual theory of happiness. One of the applications of this theory is the model known as range-frequency theory which places the range as the main point of comparison.

To see how the conditions operate, let us see an example using religion as the defining reference group characteristic. If $y_{i}$ changes, there will be a direct effect on $H_{i}$ captured by $\theta$, and an indirect effect through the change in the reference group income distribution $F\left(y_{i} / Z_{i}\right)$ captured by $\beta$. This indirect effect can be interpreted as the positional aspect of income, or the 'status return' from income. It seems reasonable to assume that, for a given $y_{i}$, the 
coefficient $(\theta)$ which captures the direct effect is the same whether you are protestant, catholic, profess other religion or have no religion. An individual obtains the same direct marginal utility of income whatever her religious beliefs. Then, the coefficient associated with the social effects $(\beta)$ is identified and will be significant if people of the same religion in the same year compare themselves, and that comparison affects their happiness.

There are two assumptions implicit in this model. First, I assume there are no endogenous effects. According to Manski's (1993) classification, these would be the effects of the average happiness of the reference group, $E\left(H_{i} / Z_{i}\right)$. I believe that an individual's happiness does not depend on the average happiness of her reference group. When looking to the Joneses we do not compare ourselves with how happy they are but with how much money they have. Second, I assume the contextual effects only come from income and not from leisure. Then, I do not include a measure of relative leisure, $g\left(L_{i}, Z_{i}\right)$. Frank (1985a, 1999) discusses why empirically income or consumption externalities are more likely than leisure externalities. Solnick and Hemenway $(1998,2005)$, and Carlsson et al. (2007), based on their survey studies, conclude that relative consumption positions are more important determinants of individual's welfare than relative leisure positions. In the end, the hypothesis I am testing is that an individual compares herself with her reference group in terms of money earned or relative position in the rat race, not in happiness nor leisure.

\section{Results for happiness}

\subsection{Importance of relative income on happiness}

I start making a regression with all the possible characteristics defining the reference groups without taking into account social comparison effects to assess their significance in the determination of happiness. In Table A2 in Appendix 2 (see Supplementary material) we see these total effects, from which I want to separate the component which corresponds to social comparison considerations. We can see that these effects do not present surprises to the connoisseur of the happiness literature. ${ }^{14}$ Reported levels of happiness are higher among women, whites, retired or those who profess a religion. On the contrary, being unemployed, widowed, divorced or separated has a large negative coefficient on reported levels of happiness.

If any of the possible $Z_{i}$ is not significant in this first regression, it is a signal against the existence of social comparison effects on the basis of that characteristic. Nevertheless, it might be not significant because of cancelling out effects

\footnotetext{
${ }^{14}$ See, for example, Oswald (1997), Helliwell (2002), Blanchflower and Oswald (2004) or Ferreri-Carbonell (2005). The pseudo-R2 is 0.083 , which is in line with the literature, and with the belief that only 8 to $20 \%$ of individual well-being depend on objective variables and hence can be explained (Kahneman et al. 1999).
} 
like the ones decribed below. Then, in principle, we cannot disregard them at this point of the study. However, the two variables non significant in Table A2 (Supplementary material), higher educational degree earned and prestige, remain non significant after the introduction of either of the two variables capturing the social comparison effects, so we disregard them for the rest of the study.

In Table A3 in Appendix 2 (see Supplementary material), I present the average income of the different groups (the omitted base case is in capital letters) which together with Table A2 (Supplementary material) contain information about the expected size of the coefficient capturing the correlated effects. To simplify the explanation, let us take a binary $Z_{i}$ like race. If the dummy variable for race takes the value zero when the individual is white, then the negative coefficient for race in the first regression means that being black is a disadvantage for happiness. However, since the average income of white men is higher than the average income of black men, the same absolute income is more likely to assure you a better relative income or position in the income distribution of the black men. Then, there is an advantage in social comparison terms of being black. This positive effect of being black is not identified in the first regression and is included in the race coefficient increasing its value. Therefore, we would expect a more negative coefficient for race in the regression including the term of social comparisons.

On the contrary, if the dummy variable for gender takes the value zero when the individual is female, then the negative coefficient for sex in the first regression means that being male is a disadvantage for happiness. However, the average income of males is higher than for females, then in social comparisons terms is also worse to be a male. In the first regression this makes the sex coefficient more negative, then in the regression including social effects we would expect this coefficient to be less negative. And the same can be said for all the $Z_{i}$.

The estimation to identify the social comparison effects, either using the ratio of incomes or the percentile (Eqs. 4 and 5), includes controls for income, linear and quadratic, ${ }^{15}$ age, linear and quadratic, health, number of children, dummy variables for sex, race, marital and work status, place of living, occupation, religion and political views, ${ }^{16}$ and finally dummies for region and year of interview. Thus, every equation is run with all the possible $Z_{i}$ variables included as controls in the $\gamma Z_{i}$ term. The estimation is robust to region cluster effects, since all other variables have individual variability.

In Table 1, I present the values of $\beta$, i.e., the marginal effects for the different definitions of the reference groups using the first variable, the ratio of incomes (Eq. 4). These effects are calculated at the sample mean of the continuous

\footnotetext{
${ }^{15}$ Since it is usually assumed that happiness is concave in income.

${ }^{16}$ The categories that are assigned a dummy variable and the category being the omitted base case for every characteristic are listed in Appendix 1 (Supplementary material).
} 
Table 1 Value of $\beta$ for different estimations of Eq. 4

\begin{tabular}{lcc}
\hline Change in probability of answering Very Happy & & \\
\hline Reference group defined by & (i) & (ii) \\
\hline Age & 0.0232 & \\
& $(0.00504)^{* * *}$ & \\
City vs. country & 0.0204 & 0.0221 \\
Marital status & $(0.00519)^{* * *}$ & $(0.00494)^{* * *}$ \\
& 0.0225 & 0.023 \\
Occupation & $(0.00516)^{* * *}$ & $(0.00624)^{* * *}$ \\
& 0.0222 & 0.0256 \\
Political views & $(0.00608)^{* * *}$ & $(0.00555)^{* * *}$ \\
& 0.0206 & 0.0236 \\
Race & $(0.00533)^{* * *}$ & $(0.00475)^{* * *}$ \\
& 0.0206 & 0.0205 \\
Region & $(0.00687)^{* * *}$ & $(0.00553)^{* * *}$ \\
& 0.0206 & 0.0204 \\
Religion & $(0.00605)^{* * *}$ & $(0.00406)^{* * *}$ \\
& 0.0205 & 0.0224 \\
Sex & $(0.00609)^{* * *}$ & $(0.00561)^{* * *}$ \\
Work status & 0.0205 & 0.0232 \\
& $(0.00497)^{* * *}$ & $(0.00526)^{* * *}$ \\
\hline
\end{tabular}

Standard errors in parentheses

Asterisks denote level of significance: ${ }^{* * *} 1 \%,{ }^{* *} 5 \%,{ }^{*} 10 \%$

Observations: 25,059; Pseudo R2 around 0.083

regressors and at the most frequent state for the dummy variables (which corresponds to a married white male, working, protestant, independent and living in the city). This table shows us the estimated change in the probability of a respondent reporting that she is Very happy $\left(H_{i}=3\right)$ when her income relative to her reference group defined by the different $Z_{i}$ increases by $100 \%$. To define the reference groups I impose a temporal restriction. I consider that individuals interviewed in one year only compare themselves with individuals interviewed in the same year. The first specification shown in the first column is the broadest definition of the groups. The reference group is just the category one belongs to for the different $Z_{i}$ in the same year. For example, a white man living in 1990 compares with all the other white men living in 1990. To narrow more the definition of the Joneses, I impose a second restriction for the second specification. As will become clear later, the reference group defined by age is the most significant and with the larger marginal effect, then I use age as the second restriction defining the groups. Hence, the second specification delimits the groups both temporarily and by age. The reference group is the category one belongs to for the different $Z_{i}$ in the same year and in the same age group. For example, a white man being thirty-six year old in 1990 compares with all the other white men being between thirty and forty years old in 1990.

Note that the coefficient in each cell is the marginal effect of interest for a different regression. As this occurs for all the tables in the paper (including the Appendix (Supplementary material)) but for three, when it is not the 
case it is indicated in those three tables. As we expected all the effects are positive, which means that the respondent is more likely to report she is Very Happy when her relative income increases. All the effects are significant at the $1 \%$ significance level. On the other hand, the marginal effects for a respondent reporting that she is Not too happy $\left(H_{i}=1\right)$ are negative as expected (see Table A4 in Appendix 2 (Supplementary material)), meaning that when her relative income increases, the probability of answering Not too happy diminishes. The a priori ambiguous effect on the intermediate answer is always negative, which means that the marginal effect for the higher happiness state is the larger.

In Table 2, I present the marginal effects using the second variable, the percentile in the reference group income distribution (Eq. 5). As in the previous table, the effects are calculated at the sample mean of the continuous regressors and at the most frequent state for the dummy variables. The direction and interpretation of the effects are the same as the previous table. The marginal effect $\partial \operatorname{Pr}\left(H_{i}=3\right) / \partial F\left(y_{i} / Z_{i}\right)$ is positive for all the reference groups and tells us that the respondent is more likely to report she is Very Happy when she climbs up one percentile in the reference group income distribution. As in the previous table, all the effects are significant at the $1 \%$ significance level. These results add to an accumulating econometric literature on relative income effects upon happiness.

Table 2 Value of $\beta$ for different estimations of Eq. 5

\begin{tabular}{lcc}
\hline Change in probability of answering Very Happy & & \\
\hline Reference group defined by & (i) & $(\mathrm{ii})$ \\
\hline Age & 0.00102 & \\
& $(0.00017)^{* * *}$ & \\
City vs. country & 0.00099 & 0.001 \\
& $(0.00019)^{* * *}$ & $(0.00012)^{* * *}$ \\
Marital status & 0.00088 & 0.00088 \\
& $(0.00019)^{* * *}$ & $(0.00018)^{* * *}$ \\
Occupation & 0.00085 & 0.0008 \\
& $(0.00018)^{* * *}$ & $(0.00019)^{* * *}$ \\
Political views & 0.00099 & 0.00102 \\
& $(0.0002)^{* * *}$ & $(0.00018)^{* * *}$ \\
Race & 0.00092 & 0.00097 \\
& $(0.0002)^{* * *}$ & $(0.00018)^{* * *}$ \\
Region & 0.00088 & 0.00083 \\
Religion & $(0.00019)^{* * *}$ & $(0.00019)^{* * *}$ \\
& 0.00096 & 0.00095 \\
Sex & $(0.00022)^{* * *}$ & $(0.00021)^{* * *}$ \\
& 0.00094 & 0.00097 \\
Work status & $(0.0002)^{* * *}$ & $(0.00018)^{* * *}$ \\
& 0.00085 & 0.00089 \\
\end{tabular}

Standard errors in parentheses

Asterisks denote level of significance: ${ }^{* * *} 1 \%,{ }^{*} 5 \%,{ }^{*} 10 \%$

Observations: 25,059; Pseudo R2 around 0.083 
In Table A5 in Appendix 2 (see Supplementary material), I present the direct effect on happiness of the different $Z_{i}$ in the corresponding regression which includes the term of social effects for the groups defined by that $Z_{i}$. We can see that the size of these coefficients for all the $Z_{i}$ is in accordance with what we expected looking at Tables A2 and A3 (see Supplementary material). Besides, the effect of real income diminishes in all the estimations. This decrease is consistent with the idea that money is not only valuable for its intrinsic purchasing power but also as a signal of social position. This second function of money is captured through my measure of social comparison effects. In particular, the total income effect of 0.0039 diminishes to an average of 0.0025 for the different estimations of Eq. 4, and to an average of 0.0016 for the different estimations of Eq. 5. From these results we can infer that the 'status return' from income ranges somewhere between two thirds and two fifths of the total effect of income. This interval is not far from the findings of the literature. For example, in the already mentioned Senik (2009) the effect of absolute income is reduced to somewhere between the half and two thirds (the coefficient diminishes from 0.27 to lower values ranging from 0.14 to 0.18 ) when the comparison effects are introduced. Similarly, Knight et al. (2006), one of the best sources of information on the magnitude of social comparisons, suggests that relative income is at least twice as important for individual happiness as actual income.

\subsection{Choosing the Joneses}

We have seen that the variable capturing social comparison effects, either the ratio of incomes or the percentile, is significant for all the reference groups. This means that individuals compare themselves, and they compare with people around them in the multiple dimensions of human life. However, we want to find the Joneses. To select which of the characteristics that define the reference groups are more relevant for social comparisons I evaluate their relative importance in a similar way as Senik (2009).

Specifically I apply two criteria. First, I make a joint regression with the relative income variables for all the reference groups defined. We eliminate the less significant and repeat the joint regression with the variables not eliminated. We repeat this procedure in a multistage fashion until ending up with the groups always significant. We run, in other words, a horse race to see which variables dominate. In Table A6 in Appendix 2 (see Supplementary material), I present the results of the three joint regressions until keeping with four reference groups always significant using the ratio of incomes. This is the significance criterion. Second, I study for these groups the actual importance of their effect on individual happiness. The magnitude of the marginal effects determines the size criterion. Finally, I select the groups defined by characteristics which satisfy both the significance and the size criteria.

Following these criteria, the reference groups defined by age, race, sex and religion are the most important for social comparisons. Although the twelve characteristics I selected to establish the reference groups were a priori 
attractive, these four are the main determinants of the Joneses. Being age the primary feature defining the people one compares with, seems reasonable since it is an immediate term of comparison. Besides, it is usually used in the literature as an a priori imposed characteristic defining the reference groups (McBride 2001 or Ferrer-i-Carbonell 2005). Race and sex are also two immediate characteristics that may well serve as a primary definition of a person, making them suitable for comparison. Though they are often mentioned in the social psychology literature (Merton and Kitt 1950, Singer 1981; or Bylsma and Major 1994), they are not so relevant in the economic literature. In a study using South African data, Kingdon and Knight (2007) find race (along with geographical proximity) as the characteristic defining the reference groups, which they attribute precisely to the special context of the racially divided South African society. The finding of religion as a characteristic defining the reference group is new (to my knowledge) in economics. In the social psychology literature, the relevance of religion in reference group theory has been recognised in some studies (Bock et al. 1983; or Clarke et al. 1990). The interpretation may be twofold. Firstly, religion provides an interpretive framework by which an individual can make sense of her experience. Secondly, the religion a person professes may be an important feature in her life, which can lead to having more contact with people with the same beliefs. In the end, one compares primarily with the people around oneself, which is consistent with our findings.

I would like to narrow more the definition of the Joneses, and try combinations of these features to find the most significant reference groups. However, I deal with a sample limitation since, as already noted, the data are 25 different cross sections of between 1,500 to 3,000 observations. In Table A7 and A8 in Appendix 2 (see Supplementary material), I present the average and minimum number of observations per group for the broadest definition of the groups (i.e., the category one belongs to for the different $Z_{i}$ in the same year), and once also delimited by age, for the group of people between thirty and forty years, ${ }^{17}$ respectively. The number of observations for these groups (the average ranging from three hundred to one hundred for most of the categories) makes me confident that the relative income measures reflect the income distribution in every group. However, if I combine further these characteristics by adding a third feature to define the reference group, the overly small number of observations per group would make any measure of relative income not to be representative.

To understand the importance of social comparisons for individual happiness, the relative income coefficient has to be put into perspective. In order to do that, the relative income effect on happiness is compared with the effect of other variables. In Table 3 we can see the impact in the higher happiness state of increasing one percentile in the income distribution of the reference group

\footnotetext{
${ }^{17}$ For the other four age groups the number of observations is similar.
} 
Table 3 Relative size of the marginal effects using race as reference group

\begin{tabular}{lcc}
\hline \multicolumn{2}{l}{ Change in probability of answering Very Happy } & \\
\hline Percentile (race) & (i) & (ii) \\
& 0.00092 & 0.00097 \\
Real income $(\$ 1,000)$ & $(0.0002)^{* * *}$ & $(0.00018)^{* * *}$ \\
& 0.00158 & 0.00147 \\
Widowed & $(0.00054)^{* * *}$ & $(0.00056)^{* * *}$ \\
& -0.169 & -0.168 \\
Divorced & $(0.00728)^{* * *}$ & $(0.0075)^{* * *}$ \\
& -0.152 & -0.151 \\
& $(0.0091)^{* * *}$ & $(0.00893)^{* * *}$ \\
\hline
\end{tabular}

In this table the cells in the same column correspond to the same regression

Standard errors in parentheses

Asterisks denote level of significance: ${ }^{* * *} 1 \%,{ }^{*} 5 \%,{ }^{*} 10 \%$

Observations: 25,059; Pseudo R2 around 0.083

defined by race, compared with the impact of increasing individual income by 1,000 dollars and with the impact of two major life events: becoming divorced or widowed (which corresponds to a discrete change in the respective dummy variable from 0 to 1$)$.

The relative size of any two coefficients provides information about the relative relevance of the variables. Normalising the coefficients, we see that the effect of climbing one percentile in the reference group income distribution has an impact of around 0.6 times the impact of an additional 1,000 dollars. This means that, concerning happiness, a one percentile increase in the income distribution of the reference group defined by race is equivalent to receiving around 600 dollars.

However, both the income and the relative income effects are small compared with the effect of becoming divorced or widowed. The influence of these non-economic variables in happiness is huge. The effect of these major life events is roughly 100 times (more for widowhood and less for divorce) the effect of the additional 1,000 dollars, while it is roughly 160 times the effect of one percentile jump. Nonetheless, these calculations should be treated cautiously because it is difficult to establish cause and effect with many of the variables that are at play, and in many cases they may interact. ${ }^{18}$ In other words, are married people happier, or are happier people more likely to get married? Are wealthier people happier, or are happier people more likely to be successful and earn more income over time? This possibility of reverse causation is an important problem, which anyway is common throughout applied economics.

\footnotetext{
${ }^{18}$ Besides, the effects of becoming divorced or widowed probably depend on the time passed since the event took place, which is not taken into account in these calculations. However, I think these comparisons to be illustrative of the size of the coefficients.
} 
The literature on happiness has addressed this issue, especially in panel data analysis, ${ }^{19}$ and mostly suggests that causation indeed runs from marriage or income to happiness. There is a separate literature in which it is concluded that marriage seems to provide a protective effect to mental well-being (see, for example, Cochrane 1996). Argyle (1999) contains further discussion of this evidence, and also argues for the casual effects of labour status or religion on happiness. In order to test the direction of causation in the incomehappiness relationship, the effect of windfalls determining income has been analysed. British lottery winners and people receiving an inheritance reported higher satisfaction scores in the following year (Gardner and Oswald 2001; or Brickman et al. 1978), which suggests causality from income to happiness. ${ }^{20}$

In any case, I believe that at this point in the history of happiness research there is no unambiguous proof about the direction of causality. Therefore, along the paper I am circumspect about causation. In the future, a better understanding of the direction of causality and the causes of happiness will provide a more secure foundation for policy recommendations.

\subsection{For whom relative income is more important}

To answer the question for whom relative income is more important, Eqs. 4 and 5 have been estimated allowing for interactions with characteristics that define different groups of people. Since the binary categories are the most significative for this type of analysis, I have made the estimation for the characteristics that divide the sample in two groups: sex (female and male), race (whites and blacks) and place of living (living in the country and living in the city). Then, the regression to identify the groups of people for which social comparisons are more important is:

$$
H_{i}=\theta y_{i}+\beta_{1} \frac{y_{i}}{E\left(y_{i} / Z_{i}\right)}+\beta_{2} \frac{y_{i}}{E\left(y_{i} / Z_{i}\right)} 1\left(Z_{i}=k\right)+\gamma^{\prime} Z_{i}+\eta^{\prime} x_{i}+\varepsilon_{i}
$$

where $k=0,1^{21}$ for the two values of $Z_{i}$. Then if $\beta_{2}$ is significant, it means that the coefficients associated with the two groups defined by $Z_{i}$ are different. If $\beta_{2}$ is positive the effect of relative income on the group defined by $Z_{i}=1$ is greater. The contrary is true if $\beta_{2}$ is negative.

As we can see in Table 4, the effect of social comparisons via income is lower for black people, for women and for people living in the city. It can be surprising that social comparison effects are larger for people living in the

\footnotetext{
${ }^{19}$ In panel analysis it is possible to consider a specific baseline well-being for each individual. See, for example, Winkelmann and Winkelmann (1998). However, as discussed in Frey and Stutzer (2002), the direction of causality cannot easily be identified even in a panel data analysis. Additional information from qualitative studies, or in the form of instrumental variables, may be necessary.

${ }^{20}$ However, in the long run these effects on happiness are of minor importance.

${ }^{21} k=0$ and then $\beta_{1}$ captures all the effect for people living in the country, for females and for white people.
} 
Table 4 Values of $\beta_{1}$ and $\beta_{2}$ in the estimation of Eq. 6

\begin{tabular}{lccc}
\hline Change in probability of answering Very Happy & & \\
\hline Reference groups & & (i) & (ii) \\
\hline City vs. country & $\beta_{1}$ & 0.0265 & 0.0284 \\
& & $(0.00578)^{* * *}$ & $(0.00613)^{* * *}$ \\
& $\beta_{2}$ & -0.0094 & -0.0095 \\
Sex & $\beta_{1}$ & $(0.00285)^{* * *}$ & $(0.0031)^{* * *}$ \\
& $\beta_{2}$ & 0.0204 & 0.0258 \\
& $\beta_{1}$ & $(0.00431)^{* * *}$ & $(0.00461)^{* * *}$ \\
Race & 0.0102 & 0.0108 \\
& $\beta_{2}$ & $(0.00363)^{* * *}$ & $(0.00377)^{* * *}$ \\
& & 0.0264 & 0.0275 \\
& & $(0.0056)^{* * *}$ & $(0.00542)^{* * *}$ \\
& & -0.0247 & -0.0244 \\
\end{tabular}

Standard errors in parentheses

Asterisks denote level of significance: ${ }^{* * *} 1 \%,{ }^{* *} 5 \%,{ }^{*} 10 \%$

Observations: 25,059; Pseudo R2 around 0.083

country. A possible explanation could be that when living in a little village the contact with neighbours is more frequent, and the information about their income is better, which could make comparison effects larger.

\subsection{Robustness checks}

I have done a number of robustness checks to test the validity of the results. As already explained, the number of observations for each group is a crucial limitation in this study and may call into question the reliability of the relative income variable. In order to deal with this problem, I have tried two different ways of increasing the number of observations per group.

The research posed thus far assumes contemporaneous effects. It may well be more realistic to assume some lag in the transmission of these effects. Then, the third specification allows an individual to compare both with people living in the same year or the year before. This doubles the number of observations for every group (but for the ones living in 1972). Then, the reference group is the category one belongs to for the different $Z_{i}$ in the same year or the year before. For example, a white man living in 1990 compares with all the other white men living in 1990 or 1989.

The fourth specification compress the categories of $Z_{i}$, making every $Z_{i}$ (except age and region which seemed little sensible) a binary variable. This increases the number of observations per group which had more than two categories in the previous specifications. The table for these new specifications using the ratio of incomes is in Table A9 in Appendix 2 (see Supplementary material).

For all the specifications, and for all the reference groups, the marginal effects on the probability of a respondent reporting that she is Very happy are positive and significant at the $1 \%$ level. On the other hand, the marginal 
effects for a respondent reporting that she is Not too happy are negative and significant at the $1 \%$ level. As in the previous specifications, the a priori ambiguous effect on the intermediate answer is always negative, thus again, the marginal effect for the higher happiness state is the larger. The results for the two criteria used to select the Joneses are also quite robust for the different specifications, so I am more confident with their reliability.

The remaining specifications, from the fifth to the eighth are just a combination of the previous ones (and the results are also in Table A9; see Supplementary material). The fifth specification just combines the second and the third. The reference group is the category one belongs to for the different $Z_{i}$ in the same year or the year before, and in the same age group. The sixth specification just combines the third and the fourth. The reference group is one of the two categories an individual belongs to for the different $Z_{i}$ in the same year or the year before. The seventh specification combines the second, the third and the fourth. The reference group is one of the two categories an individual belongs to for the different $Z_{i}$ in the same year or the year before, and in the same age group. Finally, the eight specification delimits the groups both temporarily and geographically. The reference group is the category one belongs to for the different $Z_{i}$ in the same year and in the same region.

Finally, I construct a third variable for relative income replacing the percentiles for their corresponding values in the normal cumulative distribution function. The sign and significance of the marginal effects for all the specifications and for all the reference groups confirm the results obtained with the two previous variables of relative income, as shown in Table A10 in Appendix 2 (see Supplementary material). The normal cumulative distribution function fulfils perfectly the non-linearity condition of $g\left(y_{i}, Z_{i}\right)$ necessary for identification, as discussed in Subsection 4.1. Thus, the outcomes using this third variable of relative income are especially relevant to asses the robustness of the previous results.

\section{Model for labour supply}

In the first part of the paper we have found that relative income is a significant variable in determining individual happiness. Its effect is positive which indicates relative status considerations. If these benefits of moving up in the income hierarchy are high enough, we could expect that individuals were willing to increase the amount of labour they supply in the labour market. The hours worked by an individual have a positive effect on her income and a negative effect on her happiness. So, when not taken into account, it can lead to the false conclusion that income does not increase happiness, and could then explain the Easterlin paradox. Besides, despite the sharp increase in consumption levels, labour supply ${ }^{22}$ has not declined much over the past

\footnotetext{
${ }^{22}$ Especially in the US, where our data come from (Schor 1992).
} 
100 years. The influence of social comparisons on labour supply decisions could reconcile these two facts. Therefore, in this section we are going to test if relative income affects the individual decision of labour supply. Is the income of the Joneses a significant variable to explain the number of hours an individual works?

We take up again our model in which utility depends on both absolute and relative consumption:

$$
u\left(c_{i}, \bar{c}_{i}, x_{i}\right)
$$

As standard in the literature, we introduce the relative income hypothesis in a simple way, assuming that households derive utility from the difference of their consumption with respect to the consumption of the Joneses.

$$
\widetilde{c}_{i}=c_{i}-b \bar{c}
$$

$\widetilde{c}_{i}$ is as measure of effective consumption, the consumption which really determines individual's utility, and $b$ is a measure of the importance given to social comparisons. Particularly, $b$ is the weight of relative consumption in effective consumption since if we add and substract $b c_{i}$, effective consumption becomes $\widetilde{c}_{i}=(1-b) c_{i}+b\left(c_{i}-\bar{c}_{i}\right)$.

Then, the utility function depends on effective consumption $\left(\widetilde{c}_{i}\right)$ and hours worked $\left(l_{i}\right)$. We would expect $u$ to be increasing and concave in its first argument and decreasing and convex in the second.

We use a standard definition of the keeping up with the Joneses utility functions ${ }^{23}$ which include both absolute and relative income as its arguments.

$$
u=\frac{\left(c_{i}-b \bar{c}_{i}\right)^{1-\gamma}-1}{1-\gamma}-\lambda l_{i}
$$

We maximise this utility function with respect to hours, subject to the budget constraint, $c_{i}=w_{i} l_{i}$ where $w_{i}$ is wage, which may be different for the different individuals. Taking the FOC for hours worked we get the optimal labour/leisure decision:

$$
\begin{gathered}
\frac{\partial u}{\partial l_{i}}=w_{i}\left(w_{i} l_{i}-b \bar{c}_{i}\right)^{-\gamma}-\lambda=0 \\
l_{i}^{*}=\frac{w_{i}^{(1-\gamma) / \gamma}}{\lambda^{1 / \gamma}}+\frac{b \bar{c}_{i}}{w_{i}}
\end{gathered}
$$

\footnotetext{
${ }^{23}$ For example, this is the function used in Ljungqvist and Uhlig (2000). In their model, which assumes that leisure is purely non-positional as I do, the externality of other's people consumption leads to a labour supply that is too high. They show that the task of tax policy is to undo the effect of this consumption externality and that can be accomplished by taxing consumption at a flat marginal rate, independent of the business cycle.
} 
The effects of both the importance given to social comparisons and the income of the Joneses on labour supply are positive.

$$
\begin{gathered}
\frac{\partial l_{i}^{*}}{\partial b}=\frac{\bar{c}_{i}}{w_{i}}>0 \\
\frac{\partial l_{i}^{*}}{\partial \overline{c_{i}}}=\frac{b}{w_{i}}>0
\end{gathered}
$$

It means that the more you compare yourself to the Joneses or the richer they are, the more you are going to work to surpass, catch or keep up with them.

In short, this simple model just shows a standard assertion: if the income of the Joneses or the importance given to social comparisons go up, effective consumption decreases, increasing its marginal utility. Since the optimal labour/leisure decision equates marginal utilities of consumption and leisure, this raises the marginal utility of leisure, diminishing the marginal utility of labour, and thus increasing the number of hours worked.

This model provides testable implications. We can test in the data whether social comparisons affect the number of hours worked. Since we do not have data for wages we substitute its expression derived from the budget constraint, $w_{i}=c_{i} / l_{i}$, into the FOC for hours worked. Besides, multiplying and dividing the second member of this condition by $c_{i}^{-\gamma}$ we get:

$$
l_{i}^{*}=\frac{c_{i}^{1-\gamma}}{\lambda\left[1-b\left(c_{i} / \bar{c}_{i}\right)^{-1}\right]^{\gamma}}
$$

In a one-period model, or in a model without savings, income equals consumption $\left(c_{i}=y_{i}\right)$, so that Eq. 13 can be understood as a linearised version of the optimal decision for hours worked in Eq. 12.

$$
L_{i}=\kappa y_{i}+\alpha \frac{y_{i}}{E\left(y_{i} / Z_{i}\right)}+v^{\prime} Z_{i}+\rho^{\prime} x_{i}^{\prime}+\xi_{i}
$$

where $L_{i}$ is number of hours worked by an individual, $y_{i}$ is her own income, $E\left(y_{i} / Z_{i}\right)$ is the income of her reference group and $x_{i}^{\prime}$ are other determinants of hours worked. We can see that in Eq. 13 our first measure of social comparisons appears: the income of the individual divided by the income of her reference group. We expect $\alpha$ to be significantly different from zero for the groups selected in the first part.

Before going on to present the results, two issues deserve comment. First, if Eq. 13 included the average hours worked by the reference group$E\left(L_{i} / Z_{i}\right)$-as a determinant of hours worked by an individual, there would be a problem of identification due to the presence of endogenous effects (the so-called reflection problem, Manski 1993). Nonetheless, the standard model of labour supply ${ }^{24}$ does not include this kind of interdependent behaviour. The

\footnotetext{
${ }^{24}$ See, for example, Cahuc and Zylberberg (2004).
} 
great majority of empirical labour supply studies ${ }^{25}$ do not incorporate hours of work of the reference group as a determinant of hours worked. ${ }^{26}$ Furthermore, the evidence of the non-positional aspect of leisure commented in Subsection 4.1 supports this exclusion.

Second, in this regression there is a potential problem of endogeneity since the income of the individual may well be correlated with the error term. Unobserved characteristics I cannot control for which affect hours worked such as individual laziness, hard-working or productivity can have an effect on individual income. Although the problem would be worse if we used individual wage, we must take into account this possible endogeneity. Thus, I use data for family income instead of individual income, both for the regressor $\left(y_{i}\right)$ and for the construction of the variable of relative income $\left(\frac{y_{i}}{E\left(y_{i} / Z_{i}\right)}\right)$. Family income is supposed to have a weaker relation, if any, with the error term of the equation.

\section{Results for labour supply}

We have estimated Eq. 13 for the reference groups selected in the first part: the groups defined by age, race, sex and religion. The purpose of the regression is not to estimate a state of the art labour supply function, but simply to verify if the basic pattern implied by the model is supported by the data. The dependent variable is hours worked and the explanatory variables include a list of variables typically found in studies of labour supply (Park 2005). Hence the estimation includes controls for family income, linear and quadratic, age, number of children, dummies for sex, race, place of living, occupation, marital status and education, dummies for part-time job, working for oneself and union membership, and dummies for region and year of interview. Since we include sex, race and age as regressors, we can see again the double effect of $Z_{i}$ on the dependent variable ( $L_{i}$ in this case) which requires the two conditions for the variables capturing the social comparison effects mentioned in the identification discussion for the first part. However, since the variable capturing the social comparison effects is the same as in the first part, these two conditions are already satisfied.

We present the results in Table 5. The effects are in accordance with the theoretical model. The negative sign for the coefficient associated with relative income implies that the lower is your relative income, the more hours you are going to work. For three out of four reference groups, the ones defined by age, race and sex, the coefficient is significative at the ten per cent level. In the second specification used in this paper, joining age with the other three features, the results remain negative and significant at the one per cent level.

\footnotetext{
${ }^{25}$ For a general overview, see the survey in Blundell and MaCurdy (1999).

${ }^{26}$ Blomquist (1993) and Aronsson et al. (1999) are two exceptions which show that if individual labor supply is influenced by average labour supply and this interdependence is not taken into account, it can lead to a serious bias in the predicted effects of a tax change.
} 
Table 5 Effects of relative income on hours worked

\begin{tabular}{lcc}
\hline Reference groups defined by & (i) & (ii) \\
\hline Age & -0.7895 & \\
& $(0.3203)^{* *}$ & -1.5785 \\
Sex & -4.0581 & $(0.3246)^{* * *}$ \\
& $(0.8297)^{* * *}$ & -1.1841 \\
Race & -0.8744 & $(0.2911)^{* * *}$ \\
& $(0.5297)^{*}$ & -1.2608 \\
Religion & 0.0012 & $(0.2847)^{* * *}$ \\
& $(0.5808)$ & \\
\hline
\end{tabular}

Standard errors in parentheses

Asterisks denote level of significance: ${ }^{* * *} 1 \%,{ }^{* *} 5 \%,{ }^{*} 10 \%$

Observations: 15,743; R-squared around 0.417

However, the size of the effects is very small. For example, if the income relative to the reference group defined by race decreases by $10 \%$, the number of hours worked per week increases by 0,08744 , which is less than six additional minutes per week. For the reference group defined by sex the effect is larger, a $10 \%$ decrease in relative income implies around twenty five additional minutes per week. ${ }^{27}$

The limited size of the effect may be due to the fact that individuals cannot choose exactly the number of hours they work. However, in the standard labour supply model, working hours derived from the first order condition from utility maximisation subject to the budget constraint, imply the assumption that the individual's choice set covers all possible working hours up to a maximum equal to the time endowment. This assumption does not necessarily mean that the individual has a free choice of hours with his current employer, but rather that the feasible set of jobs for the individual presents a free choice of hours. Individuals can move to employers who offer hours closer to their preferences, and employers who offer unpopular hours will have difficulties recruiting or retaining workers. Thus mobility will reduce the possible divergence among desired and observed hours of work. ${ }^{28}$ Nonetheless, taking into account the possibility that individuals cannot choose exactly how many hours they work, I look at the effect of relative income on two other labour supply decisions. First, the transition from a part-time job to a full-time job. Second, the participation decision into the labour force. ${ }^{29}$ The results are shown in Tables 6 and 7, respectively. In both cases the results

\footnotetext{
${ }^{27}$ However, in this case the assumption that $\kappa$ is the same for males and females could be non satisfactory since the marginal effect of family income on hours worked could be different for men and women.

${ }^{28}$ In support of this assumption of the standard labour supply model, Böheim and Taylor (2004), using subjective data on desired hours of work from the British Household Panel Survey (BHPS) find that men and women are able to adjust their working hours in line with preferences. They also show that workers have more possibilities to increase their working hours within the job than to reduce them, which makes it easier to keep up with the Joneses working more hours.

${ }^{29}$ The controls are the same as in the previous estimation excluding the dummies for part-time job and union membership, which had no sense in these estimations.
} 
Table 6 Effects of relative income on part-time vs. full-time job decision

\begin{tabular}{llc}
\hline Reference groups defined by & (i) & (ii) \\
\hline Age & -0.0986 & \\
& $(0.0069)^{* * *}$ & \\
Sex & -0.1755 & -0.1006 \\
& $(0.0183)^{* * *}$ & $(0.0071)^{* * *}$ \\
Race & -0.0365 & -0.0757 \\
& $(0.0172)^{* *}$ & $(0.0066)^{* * *}$ \\
Religion & 0.0295 & -0.0727 \\
& $(0.0184)$ & $(0.0064)^{* * *}$ \\
\hline
\end{tabular}

Standard errors in parentheses

Asterisks denote level of significance: ${ }^{* * *} 1 \%,{ }^{* *} 5 \%,{ }^{*} 10 \%$

Observations: 24,576; Pseudo R2 around 0.124

are consistent with the keeping up with the Joneses hypothesis. The negative sign indicates that the lower is your relative income, the higher probability of becoming a full-time worker and of entering the labour force. The effects are significant at the ten per cent level for all the groups but for the one defined by religion (and only for the part-time vs. full-time decision). For the second specification, all the effects are significant at the one per cent level.

Notwithstanding, given the potential problems commented in the previous section, I feel that these estimates of the relative income effect should be interpreted carefully. Nevertheless, the estimates of the three labour supply decisions coincide in signaling the significant effect of relative income, and the direction of this effect points directly to keeping up with the Joneses considerations. Thus, I do believe that my results support the idea that social comparisons have an influence on labour supply.

A final test to assess the validity of the results is to see if the groups of people for whom relative income is more relevant in determining their happiness, are also more influenced by relative income in their decisions of hours worked.

Remember that to answer the question for whom relative income is more important, I estimated Eq. 6, a version of Eq. 4 which included a term of interaction. To analyse if some groups are more influenced by relative income

Table 7 Effects of relative income on labour participation decision

\begin{tabular}{llc}
\hline Reference groups defined by & (i) & (ii) \\
\hline Age & -0.2476 & \\
& $(0.0101)^{* * *}$ & \\
Sex & -0.3280 & -0.2622 \\
& $(0.0248)^{* * *}$ & $(0.0102)^{* * *}$ \\
Race & -0.0371 & -0.2005 \\
& $(0.0204)^{*}$ & $(0.0090)^{* * *}$ \\
Religion & -0.0454 & -0.2113 \\
& $(0.0211)^{* *}$ & $(0.0091)^{* * *}$ \\
\hline
\end{tabular}

Standard errors in parentheses

Asterisks denote level of significance: ${ }^{* * *} 1 \%, * * 5 \%,{ }^{* * *} 10 \%$

Observations: 37,961; Pseudo R2 around 0.236 
Table 8 Values of $\alpha_{1}$ and $\alpha_{2}$ in the estimation of Eq. 14 (and $\beta_{1}$ and $\beta_{2}$ from Table 4)

\begin{tabular}{lllllll}
\hline Reference groups & & (i) & (ii) & & (i) & (ii) \\
\hline City vs. country & $\beta_{1}$ & 0.0265 & 0.0284 & $\alpha_{1}$ & -1.083 & -1.473 \\
& & $(0.00578)^{* * *}$ & $(0.00613)^{* * *}$ & & $(1.164)$ & $(0.359)^{* * *}$ \\
& $\beta_{2}$ & -0.0094 & -0.0095 & $\alpha_{2}$ & 0.344 & 0.388 \\
& & $(0.00285)^{* * *}$ & $(0.0031)^{* * *}$ & & $(0.214)^{*}$ & $(0.144)^{* * *}$ \\
Sex & $\beta_{1}$ & 0.0204 & 0.0258 & $\alpha_{1}$ & -1.638 & -1.706 \\
& & $(0.00431)^{* * *}$ & $(0.00461)^{* * *}$ & & $(0.608)^{* * *}$ & $(0.319)^{* * *}$ \\
& $\beta_{2}$ & 0.0102 & 0.0108 & $\alpha_{2}$ & -1.278 & -1.080 \\
& & $(0.00363)^{* * *}$ & $(0.00377)^{* * *}$ & & $(0.279)^{* * *}$ & $(0.213)^{* * *}$ \\
Race & $\beta_{1}$ & 0.0264 & 0.0275 & $\alpha_{1}$ & -2.311 & -1.312 \\
& & $(0.0056)^{* * *}$ & $(0.00542)^{* * *}$ & & $(1.26)^{*}$ & $(0.322)^{* * *}$ \\
& $\beta_{2}$ & -0.0247 & -0.0244 & $\alpha_{2}$ & 0.682 & 0.383 \\
& & $(0.00566)^{* * *}$ & $(0.00603)^{* * *}$ & & $(0.533)$ & $(0.305)$ \\
\hline
\end{tabular}

Standard errors in parentheses

Asterisks denote level of significance: ${ }^{* * *} 1 \%,{ }^{* *} 5 \%,{ }^{*} 10 \%$

Observations: 25,059; Pseudo R2 around 0.083 for happiness regressions

Observations: 15,743 ; R2 around 0.417 for hours regressions

in their decisions of hours worked, I proceed analogously with the labour equation.

$$
L_{i}=\kappa y_{i}+\alpha_{1} \frac{y_{i}}{E\left(y_{i} / Z_{i}\right)}+\alpha_{2} \frac{y_{i}}{E\left(y_{i} / Z_{i}\right)} 1\left(Z_{i}=k\right)+v^{\prime} Z_{i}+\rho^{\prime} x_{i}^{\prime}+\xi_{i}
$$

where $k=0,1$ for the two values of the binary variables $Z_{i}$. Then if $\alpha_{2}$ is significant, it means that the coefficients associated with the two groups defined by $Z_{i}$ are different. If $\alpha_{2}$ is negative the effect of relative income on the group defined by $Z_{i}=1$ is greater (note that $\alpha_{1}$ is negative). The contrary is true if $\alpha_{2}$ is positive.

The results shown in Table 8 support our hypothesis. The signs of $\beta_{2}$ and $\alpha_{2}$ are opposed. Negative $\beta_{2}$ in the first stage implies positive $\alpha_{2}$ in the second. It means that the groups less worried about the Joneses in their happiness equation (negative $\beta_{2}$ ) tend to work less due to social comparison effects (positive $\alpha_{2}$ which diminishes the negative effect of relative income on hours worked). This happens for women, black people, and people living in the city; while the contrary is true for men, white people and people living in the country. Therefore, this final test supports the validity of the previous results of the paper.

\section{Conclusions}

Despite being ignored for many years in the agenda of economics, happiness research has awakened. The recent outpouring of economic research on this subject is making its main conclusions becoming familiar ground. One of these is that relative income is a significant variable in determining individual happiness. My results add to an accumulating econometric literature on the negative 
effect of reference group income upon happiness, which is attributed to social comparisons. People compare themselves to others. These comparisons ${ }^{30}$ have an effect on individual behaviour. The main result of this paper is that it shows that relative income not only affects subjective well-being, but also labour supply decisions.

Before testing the importance of relative income on labour supply, it is crucial to find with what other people such comparisons are being made. Thus in the first part of the paper, the main characteristics defining the reference group one looks onto when making social comparisons are identified. The reference group is primarily defined by age, while other relevant features are race, sex and religion. The next natural step in the research could be to precise more the definition of the reference group. ${ }^{31}$ Surveys which contain direct questions about the composition of the reference groups or more complete data bases may help to address this challenge. In the same vein, how reference groups are formed and dissolved is a complicated issue that I hope will be explored in the future. In this line, Falk and Knell (2004) show in their model that the endogenously-chosen reference standards increase with individual ability, and thus people tend to compare themselves to similar others. Individuals may play an active role in the choice of their reference group, which may serve motives of self-improvement or self-enhancement.

In the second part of the paper I provide evidence, in the framework of a standard keeping up with the Joneses model, that status concerns affect the number of hours worked. If your relative income or position in your reference group is low, you will work more to surpass, catch or keep up with the Joneses. The effect of relative income on both happiness and hours worked is higher for males, white people and people living in rural areas. The consistency of these results gives support to the reliability of the happiness data used and the results obtained in the first part.

The influence of positional concerns in labour supply decisions may help to explain the Easterlin paradox, since hours worked increase income as well as decrease happiness. Besides, it is a valid reason why labour supply has not declined dramatically in the present and last century, despite the very significant rise in consumption levels. Following this line, the labour supply implications of relative income pose potential policy questions.

\footnotetext{
${ }^{30}$ Some call these comparisons envy, but they are probably best thought of as a desire to exceed, or at least keep up with relevant others. Whatever the psychological cause beneath, I provide support for their relevance on labour supply decisions.

${ }^{31}$ Once the characteristics of the reference group are identified, additional precisions could be done in a double vertical dimension. First, social comparison effects may change along the income distribution. Relative income effects may be stronger for those with higher income as McBride (2001) suggests. Second, social comparison effects may change over the course of the life cycle. At the beginning of an individual's life, social comparisons may play a larger role in her happiness and behaviour, while later in life, personal experience may become more important.
} 
A blooming literature, ${ }^{32}$ mainly theoretical, has addressed the optimal tax implications of utility functions which depend on relative income. The importance of relative income on individual utility leads to a status race, which can be perceived as self-defeating since if I do better someone else must be doing worse, and can lead to sub-optimal outcomes if it crowds-out non-status activities. Since leisure is considered a non-status activity, ${ }^{33}$ they obtain a rationale for income taxation in order to promote leisure. In other words, if we live in a Veblenian world with social comparisons, one person's increase in income has a negative externality on others because it lowers their relative income. Thus, the fight for relative positions is socially wasteful, and labour should be more heavily taxed to internalise the negative externality imposed on others. I believe that the empirical results of the second part of my paper strengthen the idea that relative income entails labour supply implications, thus providing support to the theoretical arguments of this literature. However, the number of empirical studies is still quite small, and much research is certainly warranted to increase our understanding of how relative income affects labour supply decisions. For example, the importance of the externality may depend on the structure of the reference groups (who cares about whom), their size, or to what extent they are affected. Future studies on these and related topics would help determine the extent to which the findings from this research should be incorporated into policy analysis.

Acknowledgements I wish to thank Guillermo Caruana, Stéphane Bonhomme, Olympia Bover, Cristian Bartolucci, Carlos González-Aguado, Jim Albrecht (the co-editor) and two anonymous referees for their helpful comments and suggestions.

\section{References}

Argyle M (1999) Causes and correlates of happiness. In: Kahneman D, Diener E, Schwarz N (eds) Foundations of hedonic psychology: scientific perspectives on enjoyment and suffering. Russell Sage Foundation, New York, pp 353-373

Aronsson T, Blomquist S, Sacklén H (1999) Identifying interdependent behavior in an empirical model of labor supply. J Appl Econ 14(6):607-626

Becker GS (1974) A theory of social interactions. J Polit Econ 82(6):1063-1093

Bertrand M, Mullainathan S (2001) Do people mean what they say? Implications for subjective survey data. Am Econ Rev 91(2):67-72

\footnotetext{
${ }^{32}$ The seminal contribution of this literature is considered Frank (1985b). More recently, Frank (1997), the already commented Ljungqvist and Uhlig (2000), Dupor and Liu (2003) or Layard (2005a, b, 2006) adopt similar arguments on optimal taxation in the presence of utility functions which depend on relative income.

${ }^{33}$ The status races would not distort choice if people were equally competitive in all dimensions of other people's lives. For example, if people compared their leisure with other's as intensely as they compare their earnings, the private labour-leisure choices of the individual would remain socially efficient (Layard 2005b).
} 
Blanchflower D, Oswald A (2004) Well-being over time in Britain and the USA. J Public Econ 88(7-8):1359-1386

Blomquist S (1993) Interdependent behaviour and the effect of taxes. J Public Econ 51(2):211-218

Blundell R, MaCurdy T (1999) Labor supply: a review of alternative approaches. In: Ashenfelter O, Card D (eds) Handbook of labor economics. Elsevier Science, Amsterdam, pp 1559-1695

Bock EW, Beeghley L, Mixon AJ (1983) Religion, socioeconomic status, and sexual morality: an application of reference group theory. Sociol Q 24(4):545-559

Böheim R, Taylor M (2004) Actual and preferred working hours. Br J Ind Relat 42(1):149-166

Bowles S, Park Y (2005) Emulation, inequality, and work hours: was Thorstein Veblen right? Econ J 115(507):397-412

Brickman P, Coates D, Janoff-Bulman R (1978) Lottery winners and accident victims. Is happiness relative? J Pers Soc Psychol 36(8):917-927

Brown G, Gardner J, Oswald A, Qian J (2008) Does wage rank affect employees' well-being? Ind Relat 47(3):355-389

Bylsma WH, Major B (1994) Social comparisons and contentment: exploring the psychological costs of the gender wage gap. Psychol Women Q 18(2):241-249

Cahuc P, Zylberberg A (2004) Labor economics. Massachusetts Institute of Technology Press, Cambridge

Carlsson F, Johansson-Stenman O, Martinsson P (2007) Do you enjoy having more than others? Survey evidence of positional goods. Economica 74(296):586-598

Clark A, Oswald A (1996) Satisfaction and comparison income. J Public Econ 61(3):359-381

Clark A, Frijters P, Shields MA (2008) Relative income, happiness and utility: an explanation for the Easterlin Paradox and other puzzles. J Econ Lit 46(1):95-144

Clarke L, Beeghley L, Cochran JK (1990) Religiosity, social class, and alcohol use: an application of reference group theory. Sociol Perspect 33(2):201-218

Cochrane R (1996) Marriage and madness. Psychol Rev 3:2-5

Diener E (1984) Subjective well-being. Psychol Bull 95(3):542-575

Duesenberry JS (1949) Income, savings and the theory of consumer behavior. Harvard University Press, Cambridge

Dupor B, Liu WF (2003) Jealousy and equilibrium overconsumption. Am Econ Rev 93(1):423-428

Easterlin RA (1973) Does money buy happiness? Public Interest 30:3-10

Easterlin RA (1974) Does economic growth improve the human lot? Some empirical evidence. In: David PA, Melvin WR (eds) Nations and households in economic growth: essays in honor of Moses Abramowitz. Academic Press, New York, pp 89-125

Falk A, Knell M (2004) Choosing the Joneses: endogenous goals and reference standards. Scand J Econ 106(3):417-435

Ferrer-i-Carbonell A (2005) Income and well-being: an empirical analysis of the comparison income effect. J Public Econ 89(5-6):997-1019

Ferrer-i-Carbonell A, Frijters P (2004) How important is methodology for the estimates of the determinants of happiness? Econ J 114(496):641-659

Festinger L (1954) A theory of social comparison processes. Human Relat 7(2):117-140

Frank RH (1985a) The demand for unobservable and other nonpositional goods. Am Econ Rev 75(1):101-116

Frank RH (1985b) Choosing the right pond: human behavior and the quest for status. Oxford University Press, New York

Frank RH (1997) The frame of reference as a public good. Econ J 107(445):1832-1847

Frank RH (1999) Luxury fever: why money fails to satisfy in an era of excess. Free Press, New York

Frey B, Stutzer A (2002) What can economists learn from happiness research? J Econ Lit 40(2):402-435

Gali J (1994) Keeping up with the Joneses: consumption externalities, portfolio choice, and asset prices. Journal of Money, Credit, and Banking 26(1):1-8

Gardner J, Oswald A (2001) Does money buy happiness? a longitudinal study using data on windfalls. Mimeo, Department of Economics, Warwick University

Helliwell JF (2002) How's life? Combining individual and national variables to explain subjective well-being. Econ Model 20(2):331-360 
Hirschman A, Rothschild M (1973) The changing tolerance for income inequality in the course of economic development. Q J Econ 87(4):544-566

Kahneman D, Diener E, Schwarz N (eds) (1999) Foundations of hedonic psychology: scientific perspectives on enjoyment and suffering. Russell Sage Foundation, New York

Kingdon GG, Knight J (2007) Community, comparisons and subjective well-being in a divided society. J Econ Behav Organ 64(1):69-90

Knight J, Song L, Gunatilaka R (2006) Subjective well-being and its determinants in rural China. China Econ Rev 38(1):113-124

Layard R (2005a) Happiness: lessons of a new science. Penguin Books, London

Layard R (2005b) Rethinking public economics: the implications of rivalry and habit. In: Bruni L, Porta PL (eds) Economics and happiness: framing the analysis. Oxford University Press, London, pp 147-169

Layard R (2006) Happiness and public policy: a challenge to the profession. Econ J 116(509):C24$\mathrm{C} 33$

Lévy-Garboua L, Montmarquette C (2004) Reported job satisfaction: what does it mean? J SocioEcon 33(2):135-151

Ljungqvist L, Uhlig H (2000) Tax policy and aggregate demand management under catching up with the Joneses. Am Econ Rev 90(2):356-366

Luttmer E (2005) Neighbors as negatives: relative earnings and well-being. Q J Econ 120(3):9631002

Manski C (1993) Identification of endogenous social effects: the reflection problem. Rev Econ Stud 60(2):531-542

McBride M (2001) Relative-income effects on subjective well-being in the cross section. J Econ Behav Organ 45(3):251-278

Melenberg B (1992) Micro-economic models of consumer behaviour and welfare. PhD thesis, Tilburg University

Merton RK, Kitt AS (1950) Contributions to the theory of reference group behavior. In: Merton RK, Lazarsfeld P (eds) Continuities in social research: studies in the scope and method of the American soldier. Free Press, New York, pp 40-105

Neumark D, Postlewaite A (1998) Relative income concerns and the rise in married women's employment. J Public Econ 70(1):157-183

Oswald A (1997) Happiness and economic performance. Econ J 107(445):1815-1831

Parducci A (1995) Happiness, pleasure, and judgment: the contextual theory and its applications. Lawrence Erlbaum Associates, Mahwah

Park Y (2005) The second paycheck to keep up with the Joneses: relative income concerns and labor market decisions of married women. Working paper 2005-10, Department of Economics, University of Massachusetts Amherst

Pollak RA (1976) Interdependent preferences. Am Econ Rev 66(2):309-320

Ravallion M, Lokshin M (2001) Identifying welfare effects from subjective questions. Economica 68(271):335-357

Schor J (1992) The overworked American: the unexpected decline of leisure. Basic Books, New York

Senik C (2004) When information dominates comparison: a panel data analysis using Russian subjective data. J Public Econ 88(9-10):2099-2123

Senik C (2008) Ambition and jealousy: income interactions in the 'old' Europe versus the 'new' Europe and the United States. Economica 75(299):495-513

Senik C (2009) Direct evidence on income comparison and their welfare effects. J Econ Behav Organ 72(1):408-424

Singer E (1981) Reference groups and social evaluations. In: Rosenberg M, Turner RH (eds) Social pyschology: sociological perspectives. Basic Books, Nwe York, pp 66-93

Sloane PJ, Williams H (2000) Job satisfaction, comparison earnings, and gender. Labour 14(3):473-501

Smith A (1759) The theory of moral sentiments. D. D. Raphael and A. L. Macfie, Liberty Fund, Indianapolis

Solnick S, Hemenway D (1998) Is more always better? A survey on positional concerns. J Econ Behav Organ 37(3):373-383 
Solnick S, Hemenway D (2005) Are positional concerns stronger in some domains than in others? Am Econ Rev 95(2):147-151

Stark O, Taylor JE (1989) Relative deprivation and international migration. Demography 26(1): $1-14$

Stark O, Taylor JE (1991) Migration incentives, migration types: role of relative deprivation. Econ J 101(408):1163-1178

Veblen T (1899) The theory of leisure class. Modern Library, New York

Winkelmann L, Winkelmann R (1998) Why are unemployed so unhappy? Evidence from panel data. Economica 65(257):1-15 